\title{
Pulmonary Hypertension in Sickle Cell Disease Patients: Correlation of TRV Jet with Serum NT-Pro BNP Concentration
}

\author{
Zeba Jabeen ${ }^{1}$, Anil Pathare ${ }^{1}$, Adil Al Riyami ${ }^{3}$, Mohammed Al Huneini ${ }^{1}$, Khalid Al Rasaadi ${ }^{4}$, \\ Majdah Al-Raiesi ${ }^{5}$, Naglaa Fawaz $^{1}$ and Salam Alkindi ${ }^{1,2, *}$ \\ ${ }^{I}$ Department of Haematology, Sultan Qaboos University Hospital, Muscat, Oman. \\ ${ }^{2}$ Sultan Qaboos University, College of Medicine \& Health Sciences, Muscat, Oman. \\ ${ }^{3}$ Department of Medicine, Sultan Qaboos University Hospital, Muscat, Oman. \\ ${ }^{4}$ Department of Biochemistry, Sultan Qaboos University Hospital, Muscat, Oman. \\ ${ }^{5}$ Department of Clinical Physiology, Sultan Qaboos University Hospital, Muscat, Oman.
}

\begin{abstract}
Objectives: The aim of this study was to determine the prevalence of pulmonary hypertension [PH] and correlate it with the laboratory markers of hemolysis and serum NT-pro brain natriuretic peptide [BNP] concentrations in Sickle cell disease $[\mathrm{SCD}]$ patients from Oman.

Methods: A cohort of 115 SCD patients was investigated with complete blood counts, blood chemistry, Serum NT-proBNP levels, imaging studies and cardiac evaluation with a 12-lead electrocardiogram and Doppler echocardiogram. They were prospectively screened for pulmonary hypertension $[\mathrm{PH}]$ with echocardiography, defined as a tricuspid regurgitation flow velocity of $>$ or $=2.5 \mathrm{~m} / \mathrm{sec}$.

Results: Amongst the 73 evaluable patients, those with $\mathrm{PH}[\mathrm{n}=7]$ had a median age of 32 years with an interquartile range (IQR) of 25.5-34 years, and a prevalence of 9.6\%. No statistically significant differences were detected in the haematological parameters, serum blood chemistry and ECG parameters in patients with and without PH. However, in the PH patients, there was an increased plasma NT pro-BNP levels [p<0.006], and serum CRP levels [p<0.003][Mann Whitney U test]. Furthermore, the differences in the indirect bilirubin levels were statistically significant for one tailed comparison [p $<0.04$, Mann Whitney $U$ test]. The serum NT-pro BNP levels were also significantly correlated with $\mathrm{PH}[\mathrm{r}=0.368, \mathrm{p}<0.025]$.

Conclusions: The median age of PH patients was decade higher with median serum NT-pro BNP levels being two-fold higher and significantly correlated with PH. The significant correlation between serum indirect bilirubin and PH may implicate haemolytic parameters in the pathogenesis of $\mathrm{PH}$.
\end{abstract}

Keywords: Pulmonary hypertension, NT-pro BNP, sickle cell disease.

doi.org/10.21089/njhs.11.0005

\section{INTRODUCTION}

Sickle cell Disease (SCD) is a multi-system disorder caused by an abnormal hemoglobin $\mathrm{HbS}$ produced due to the replacement of glutamic acid with valine in the $\beta$-chains [1]. Upon deoxygenation in capillaries of peripheral tissues and organs, red blood cells (RBC's) containing the abnormal $\mathrm{HbS}$ become rigid and sickled in shape leading to obstruction of blood flow through small vessels, thereby causing painful vasoocculsive (VOC) events that lead to

*Address correspondence to this author at the Consultant Haematologist, Department of Haematology, College of Medicine \& Health Sciences, Sultan Qaboos University, P. O. Box 35, Muscat 123, Sultanat-e-Oman. E-mail: sskindi@yahoo.com bone, tissue and organ damage [2]. Thus, because of the structural change to the RBC's caused by $\mathrm{HbS}$, the RBC lifespan is greatly reduced resulting in a chronic hemolytic anemia.

However despite the apparent simplicity of the genotype, there is a considerable variability in the phenotypic presentation of this disease [2-4] with some of this variability being attributed to genetic or epigenetic factors as well as to social and environmental factors.

Although the most common presenting symptoms in SCD is painful crisis due to the VOC process, pulmonary hypertension $(\mathrm{PH})$ has been increasingly described as a cause of morbidity and mortality with case reports or case series 
because of the improved survival of SCD patients to $5^{\text {th }}$ and $6^{\text {th }}$ decades [5-7]. The reported high prevalence of $\mathrm{PH}$ is variable and is believed to be due to the combination of chronic hemolysis leading to nitrous oxide (NO) scavenging by the released free plasma hemoglobin, along with perturbation of the endothelium leading to increased reactive oxygen species generation, and activation of the coagulation system with platelet aggregation [7-9].

Recent studies have also suggested that rapid scavenging of NO by cell-free hemoglobin, which is found in high concentrations under conditions of hemolysis, may limit NO bioavailability in sickle cell disease [7], whereas inhaled NO augments its transport on sickle cell hemoglobin [10]. Several case reports have also demonstrated significant improvement in $\mathrm{PH}$, among children with acute chest syndrome after inhaled NO therapy [11-12]. Furthermore, Morris C et al. [13] have also documented a relationship between L-arginine-nitric oxide pathway and vaso-occlusion in SCD. Their study documented low arginine levels during VOC and they proposed that it reflected a state of acute substrate depletion with resultant decrease in NO production.

$\mathrm{PH}$, alters the pulmonary vasculature leading to a narrowing of the lumen with reduced blood flow [14]. Moreover, owing to the increased pulmonary vascular resistance, on one hand there is a reduced ability of the right ventricle to pump blood to the pulmonary circuit, while, on the other hand the patient will start to complain of increasing shortness of breath. Furthermore, ventricular hypertrophy or stretching leads to physiological expression of cardiac BNP and thus elevated circulating serum BNP levels [15]. Therefore elevated serum BNP levels is considered a useful marker for right ventricular dysfunction and can predict outcomes $[15,16]$.

The aim of this study was to determine the prevalence of $\mathrm{PH}$ in SCD patients by echocardiography and correlate it with the laboratory parameters of hemolysis and serum NT-pro BNP concentrations in SCD patients.

\section{MATERIALS AND METHODS}

115 SCD patients (97 SS homozygotes; $18 \mathrm{~S} \beta^{0}$ Thal double heterozygotes) were prospectively enrolled in the study after an informed consent between August 2012 to July 2013. It was a prospective cross-sectional cohort study and all patients were evaluated in steady state [defined as the period between the VOC or painful crises, during which the patient feels well, with no acute illness or pain or infection] [2]. Exclusion criteria included severe renal insufficiency [GFR < 30], severe liver disease, severe restrictive lung disease, systemic hypertension, significant obesity [BMI >30] or underlying cardiovascular disease.

Blood was obtained by venipuncture into Vacutainer tubes with EDTA anticoagulant, 3.2\% sodium citrate and plain tubes. Complete blood counts were performed with an electronic cell counter (Abbott CELL-DYN ${ }^{\circledR}$ Sapphire, Abbott Diagnostics, Abbott Park, IN). Hemoglobin phenotype was studied by cation-exchange high-performance liquid chromatography (Bio-Rad VARIANT, Bio-Rad Laboratories, Hercules, CA) after a written informed consent.

The SCD genotype was further confirmed by Sanger sequencing of the patient's DNA. Several biochemical parameters of renal and liver function were measured by Beckman Synchrom CX7 analyzer including serum $\mathrm{LDH}(\mathrm{U} / \mathrm{L})$, serum haptoglobin(U/L), AST(U/L), ALT(U/L), serum total, direct and indirect bilirubin $(\mathrm{mmol} / \mathrm{L})$, serum $\operatorname{sodium}(\mathrm{mmol} / \mathrm{L})$, potassium $(\mathrm{mmol} / \mathrm{L})$, chlorides $(\mathrm{mmol} / \mathrm{L})$, BUN $(\mathrm{mmol} / \mathrm{L})$ and serum creatinine $(\mathrm{mmol} / \mathrm{L})$. C-reactive protein $(\mathrm{CRP})$ was estimated by rate nephelometry $(\mathrm{mg} / \mathrm{L})$. Additional investigations included X-ray chest, 12-lead ECG, arterial blood gas study, pulmonary function tests, pulse oximetry and echocardiography. Serum NT-proBNP levels $(\mathrm{pg} / \mathrm{ml})$ were estimated by a sandwich ELISA using polyclonal antibodies (Elecsys analyzer; Roche Diagnostics, Mannheim, Germany) in 73 patients.

All the patients underwent a complete physical examination. Cardiac evaluation was performed by a senior cardiologist with a resting 12-lead electrocardiography including measurements of the heart rate, cardiac axis, PR interval, QRS duration, and QTc interval. Doppler echocardiography was performed on all patients using the General Electronics Vivid E9 model in the clinical physiology department using a standard equipment and $3.7 \mathrm{MHz}$ transducer to obtain pulmonary artery flow acceleration times. $\mathrm{PH}$ was defined as the calculated mean pulmonary artery pressure $>25 \mathrm{mmhg}$ at rest or $>30 \mathrm{mmhg}$ with exercise. Echocardiographically, $\mathrm{PH}$ was defined as Tricuspid regurgitant jet velocity (TRV) $>2.5 \mathrm{~m} / \mathrm{s}$, since it corresponded to pulmonary artery pressure of $25-30 \mathrm{~mm}$ of $\mathrm{Hg}$ [17].

\section{STATISTICS}

Statistical analysis was performed using STATA ver. 10.0 (StataCorp, College Station, Texas, USA). Continuous variables were assessed for normality using the Kolmogorov-Smirnov test and the data presented as mean \pm standard deviation. If the variables were not normally distributed, the data is presented as median and interquartile range [IQR]. Comparisons between variables were then performed using Pearson's correlation test, the Student's unpaired two-tailed ' $t$ ' test or Mann-Whitney $U$ test where appropriate. A $\mathrm{p}$ value of $<0.05$ was considered as significant.

\section{RESULTS}

115 SCD patients were consecutively enrolled in steady state, with no attempt being made to choose the patients by genotype. They comprised of 57 females (49.6\%), with a 
median age of 24[interquartile range [IQR] of 20-29 years (Table 1). Biochemical assessment of liver function revealed serum ALT [median $21 \mathrm{U} / \mathrm{L}$; IQR 14-39], serum AST [median $33 \mathrm{U} / \mathrm{L}$; IQR 23-42], serum ALP [median $88 \mathrm{U} / \mathrm{L}$; IRQ 62-137], total serum bilirubin [median $29 \mu \mathrm{mol} / \mathrm{L}$, IQR 20-43] indirect serum bilirubin [median $26 \mu \mathrm{mol} / \mathrm{L}$, IQR 1441] in keeping with the nature of their haemolytic disease. Serum LDH was median 378 U/L, IQR 273-509. Evaluation of renal function revealed serum. Creatinine [median 41 $\mathrm{mmol} / \mathrm{L}, \mathrm{IQR} 33-50]$ and serum urea [mean $2.7 \mathrm{mmol} / \mathrm{L}, \mathrm{SD}$ $\pm 1.3]$.

Table 1. Characteristics of SCD patients in the study cohort [n=115].

\begin{tabular}{|c|c|}
\hline Characteristic & Value \\
\hline \multicolumn{2}{|l|}{ Disease Phenotype } \\
\hline Hemoglobin SS & $97(84)$ \\
\hline $\mathrm{S} \beta^{0}$ thalassemia & $18(16)$ \\
\hline Age in years & $24(20-29)$ \\
\hline Female sex & $57(49.6)$ \\
\hline BMI & $22.3(20.02-23.2)$ \\
\hline History of vaso-occlusive crisis & $69(60)$ \\
\hline History of acute chest syndrome & $52(45)$ \\
\hline History of splenectomy & $19(17)$ \\
\hline Hydroxyurea therapy & $49(43)$ \\
\hline Regular transfusion program & $74(64)$ \\
\hline Hemoglobin - g/dl, & $9.6 \pm 1.4$ \\
\hline White-cell count $-10 \mathrm{X}^{9} / \mathrm{L}$, & $9.7(7-12)$ \\
\hline Platelet count $-10 \mathrm{X}^{9} / \mathrm{L}$ & $319.5(182.75-480.5)$ \\
\hline
\end{tabular}

\begin{tabular}{|l|c|}
\hline Blood urea nitrogen $-\mathrm{mmol} / \mathrm{L}$, & $2.7 \pm 1.3$ \\
\hline $\mathrm{S}$. Creatinine $-\mathrm{mmol} / \mathrm{L}$, & $41(33-50)$ \\
\hline $\mathrm{GFR}-\mathrm{ml} / \mathrm{min} / 1.73 \mathrm{~m}^{2}$ & $173.5(107.2-251.75)$ \\
\hline Lactate dehydrogenase - U/L, & $378(273-509)$ \\
\hline Bilirubin - $\mu \mathrm{mol} / \mathrm{L}$ & \\
\hline Total, & $29(20-43)$ \\
\hline Direct, & $7(5-10)$ \\
\hline Indirect, & $26(14-41)$ \\
\hline Aspartate aminotransferase - U/L, & $33(23-42)$ \\
\hline Alanine aminotransferase - U/L, & $21(14-39)$ \\
\hline Alkaline phosphatase- U/L, & $88(62-137)$ \\
\hline
\end{tabular}

Values are expressed either $\mathrm{n}(\%)$ or mean $\pm \mathrm{SD}$ or median (interquartile range).

Table 2 shows the comparison in the evaluable cohort of 73 SCD patients in whom both data on NT-pro BNP levels and TRV jet were available. No statistically significant differences were detected in the $\mathrm{Hb}$ levels, absolute retic counts, white cell counts, platelet count, LDH, BUN, S. creatinine, total serum bilirubin, ALT, AST or alkaline phospatase between patients with and without $\mathrm{PH}$. In PH patients, there was an increased plasma NT pro-BNP levels. [p<0.006], and CRP level [p<0.003] [Mann Whitney U test], however, for indirect bilirubin levels the differences were significant only for one tailed comparison $[\mathrm{p}<0.04$, Mann Whitney $\mathrm{U}$ test]. The serum NT-pro BNP levels were significantly correlated with $\mathrm{PH}[\mathrm{r}=0.368, \mathrm{p}<0.025]$.

Table 3 shows that the cumulative prevalence of $\mathrm{PH}$ was $9.6 \%[\mathrm{n}=7]$ in this SCD cohort. Furthermore, the median Tricuspid regurgitant (TR) Max peak gradient was 44.21 mmHg (IQR-32.48 to 60.53) using the TR jet velocity of $\geq 2.5 \mathrm{~m} / \mathrm{s}$.

Table 2. Comparison of Clinical and Laboratory parameters in SCD patients with $(n=7)$ and without $(n=66)$ PH who had Echocardiographic evaluation.

\begin{tabular}{|l|c|c|c|}
\hline & Without PH & With PH & p value \\
\hline Age (years) & $24(20-28)$ & $32(25.5-34)$ & $0.03 * * \$$ \\
\hline Male Sex, n(\%) & $26(39)$ & $7(100)$ & \\
\hline BMI & $22.4(20.41-29.8)$ & $24.65(22.4-28.75)$ & $0.98 * *$ \\
\hline
\end{tabular}


Table 2. contd...

\begin{tabular}{|c|c|c|c|}
\hline & Without PH & With PH & p value \\
\hline Hemoglobin-g/dl & $9.41 \pm 1.31$ & $9.45 \pm 1.43$ & $0.859 *$ \\
\hline Absolute Retic count $-10 X^{9} / \mathrm{L}$ & $204(138.5-282.5)$ & $217.5(83.2-351.75)$ & $0.795^{* *}$ \\
\hline White-cell count $-10 X^{9} / \mathrm{L}$ & $9.7(7-12)$ & $10.2(5.5-11.7)$ & $0.98^{* *}$ \\
\hline Platelet Count $-10 X^{9} / \mathrm{L}$ & $321(182.5-483.5)$ & $359.5(229.5-508.57)$ & $0.616^{* *}$ \\
\hline Blood urea nitrogen- $\mathrm{mmol} / \mathrm{L}$ & $3.38 \pm 1.8$ & $3.52 \pm 1.22$ & $0.842 *$ \\
\hline S. Creatinine- $\mu \mathrm{mol} / \mathrm{L}$ & $40.5(33-48)$ & $47.5(30.25-60.25)$ & $0.275^{* *}$ \\
\hline GFR $\mathrm{ml} / \mathrm{min} / 1.73 \mathrm{~m}^{2}$ & $159.5(107.25-196)$ & $209(178.5-252)$ & $0.89 * *$ \\
\hline Lactate dehydrogenase- $\mathrm{U} / \mathrm{L}$ & $377(266.5-500.75)$ & $468.5(359.75-591.5)$ & $0.25^{* *}$ \\
\hline Total Serum Bilirubin- $\mu \mathrm{mol} / \mathrm{L}$ & $29(19-42.25)$ & $37(21.75-125.25)$ & $0.25^{* *}$ \\
\hline Direct Serum Bilirubin- $\mu \mathrm{mol} / \mathrm{L}$ & $7(5-10)$ & $12(5.5-117.75)$ & $0.05^{* * \#}$ \\
\hline Indirect Serum Bilirubin- $\mu \mathrm{mol} / \mathrm{L}$ & $17.5(13.3-28)$ & $28(17.5-48)$ & $0.04 * * \#$ \\
\hline Aspartate aminotransferase-U/L & $31(22-42)$ & $31.5(23-37)$ & $0.887 * *$ \\
\hline Alanine aminotransferase-U/L & $21.5(13-39)$ & $19.5(14.75-42)$ & $0.96^{* *}$ \\
\hline Alkaline phosphatase-U/L & $86.5(43.9-192.25)$ & $89(76.5-178)$ & $0.636 * *$ \\
\hline CRP-mg/L & $7.5(3-23.25)$ & $34(19.5-42)$ & $0.003^{* * \$}$ \\
\hline NT pro-BNP-pg/ml & $113.7(43.9-192.25)$ & $211.6(170.575-1131.25)$ & $0.006^{* *} \$$ \\
\hline
\end{tabular}

Values are mean $\pm \mathrm{SD}$ or median (interquartile range)

* Student's t test

** Mann-Whitney U test [\# 1-tail significance, \$-2 tail significance]

PH- Pulmonary Hypertension

BNP- Brain natriuretic peptide

Table 3. Echocardiographic evaluation of Right ventricular function in SCD patients with Pulmonary Hypertension [ $\mathrm{n}=7$ ].

\begin{tabular}{|l|c|c|}
\hline & Median & Interquartile Range \\
\hline TR Max peak gradient (mmHg) & 44.21 & $32.48-60.53$ \\
\hline Rt. Ventricular Systolic Pressure, $(\mathrm{mmHg})$ & 43.61 & $40.92-72.5$ \\
\hline Rt. Atrial Pressure, $(\mathrm{mmHg})$ & 7.325 & $1.83-9.34$ \\
\hline
\end{tabular}

\section{DISCUSSION}

Doppler ultrasound echocardiography is the most commonly used method to diagnose PH. It is non-invasive and can be repeated as necessary, but is operator dependent. TRV jet measurement is used as a surrogate marker of right ventricular stroke volume by acquiring continuous wave
Doppler ultrasound signals in the parasternal axis of the apical view. Pulmonary arterial pressure was estimated using the Bernoulli equation and PH was defined as TRV $>2.5 \mathrm{~m} / \mathrm{s}$, since it corresponded to pulmonary artery pressure of 25 $30 \mathrm{~mm}$ of $\mathrm{Hg}[14,17]$. 
Moreover, an elevated pulmonary artery systolic pressure calculated from the TRV jet that is greater than $2.5 \mathrm{~m} / \mathrm{s}$ is defined as abnormal, based on the fact that this value is two standard deviations above the mean and is also corroborated by confirmatory studies in normal subjects with right heart catheterization [18].

In this prospective cross-sectional cohort study, based on the TRV jet observed by echocardiography, we found that the cumulative prevalence of $\mathrm{PH}$ amongst these patients was $9.6 \%$. $\mathrm{PH}$ is an important complication of SCD as it is associated with a several fold increase in mortality [14-16]. Hence it is desirable to screen adult SCD patients to alert the treating physician about its presence, so that appropriate management decisions can be made.

A literature review shows that the prevalence of $\mathrm{PH}$ is variable and this variability can also be related to the method of defining how PH is diagnosed [2, 6, 18-20]. Minniti et al. [19] reported $11 \%$ prevalence of PH using TRV jet in pediatric SCD population, whereas, Aliyu et al. [6] and Oguanobi et al. [20] reported $25 \%$ and $42 \%$ respectively in Nigerian adult SCD patients. Most of the literature reporting $\mathrm{PH}$ in SCD show that screening for $\mathrm{PH}$ was generally performed by measuring the TRV jet and uniformly using $>2.5 \mathrm{~m} / \mathrm{sec}$ as the cut-off to demonstrate clinically severe $\mathrm{PH}$.

However, there are few studies that report the prevalence of $\mathrm{PH}$ using invasive techniques like right heart catheterization which is the putative gold standard for the diagnosis of PH. Parent et al. [21] reported prevalence of $\mathrm{PH}$ of $27 \%$ based on TRV jet $>2.5 \mathrm{~m} / \mathrm{sec}$; but could confirm significant $\mathrm{PH}$ in only $6 \%$ in that same patient cohort by right heart catheterization. Thus, although the measurement TRV jet is a validated screening method for estimation of $\mathrm{PH}$ [14], it is a surrogate measure and is likely to overestimate the actual prevalence of severe PH. Nevertheless, being a non-invasive method it still has a place as a screening measure before subjecting patients to invasive techniques, although guidelines mandate a confirmatory right heart catheterization study for making treatment decisions as standard of care [22].

NT-pro BNP is a cardiac neurohormone secreted from the membrane granules in cardiac ventricles in response to volume expansion and pressure overload. Levels of NT-pro BNP are elevated in cardiac disease states associated with increased ventricular stretch. NT-pro BNP produces arterial $\&$ venous vasodilatation $\&$ its levels are a reflection of left ventricular diastolic filling pressure thus correlated with pulmonary capillary wedge pressure. Levels less than $100 \mathrm{pg} / \mathrm{ml}$ exclude heart failure but levels more than $100 \mathrm{pg} / \mathrm{ml}$ is considered positive \& indicative of heart failure $\&$ increased ventricular filling pressure as occurs with systolic \& diastolic dysfunction heart failure [15, 23, 24].

Machado et al. [15] showed that NT-pro BNP levels were associated with increased mortality in adult Cooperative Study of Sickle Cell Disease cohort patients from USA when using a cut-off of $\geq 160 \mathrm{ng} / \mathrm{l}$, giving a $78 \%$ positive predictive value for PH. Furthermore, a statistically significant correlation has also been reported between NT-pro BNP values and right ventricular end diastolic pressure with receiver operator characteristic curve analysis showing that a cut-off value of $395.34 \mathrm{pg} / \mathrm{mL}$ had a sensitivity of 0.69 and specificity of 1.0 [25]. Our study shows that there was a twofold higher NT-pro BNP levels which were statistically significant in patients with $\mathrm{PH}$ with a median NT-pro BNP levels of $211.6 \mathrm{pg} / \mathrm{ml}$ (Table 2). Higher NT-proBNP levels signify that the heart is under significant stress and the realization of this is of vital importance, as elevated NT- pro BNP levels are associated with a 7.8 fold increase in the odds of severe functional impairment associated with an increased cardiac mortality and sudden death [14-16].

There could be several reasons for the elevation of pulmonary arterial pressure in SCD. Factors affecting the risk of PH in SCD include age, severity of hemolysis, systemic hypertension, asthma, iron overload, chronic liver and heart diseases [26, 27]. Increased cardiac output owing to severe anemia alone can potentially secondarily elevate pulmonary artery pressure in presence of normal pulmonary vascular resistance. Similarly, increased blood viscosity will also elevate pulmonary arterial pressure and thus the surrogate estimation of PH by TRV jet measurements. Furthermore, and in contrast, absence of TRV jet does not always exclude patients from having $\mathrm{PH}$ [28]. Thus the limited positive predictive value of an elevated TRV jet may be explained in part by physiologic variations and inaccuracies of the Doppler measurement. These are pitfalls that need to be avoided when inferring the significance of $\mathrm{PH}$ in SCD patients.

Our patients with $\mathrm{PH}$ were at least a decade older than patients who did not have PH (Table 2) and showed significantly elevated right ventricular systolic pressures with relatively normal right atrial pressures (Table $\mathbf{3}$ ). Furthermore, we also found a significant correlation serum NT-pro BNP levels and PH as reported in literature [23-25]. Nevertheless, we also did not see any diastolic dysfunction that may have contributed to $\mathrm{PH}$ in our study patients, hence excluding it as a cause for the elevated TRV jet in these patients.

\section{CONCLUSION}

Our study shows that demonstration of $\mathrm{PH}$ by noninvasive transthoracic Doppler echocardiography measuring the TRV jet to estimate the pulmonary artery systolic pressure is useful and as reported in literature is a validated screening tool; but needs to be complemented by right heart catheterization for a definitive diagnosis as mandated by current guidelines. But this means invasive intervention. Furthermore, it appears that the combination of elevated NTproBNP levels and an abnormal TRV jet has an equally significant diagnostic and prognostic significance. 


\section{ACKNOWLEDGEMENT}

Sultan Qaboos University hospital and authors.

\section{CONFLICT OF INTEREST}

The authors report no conflicts of interest. The authors alone are responsible for the content and writing of this article.

\section{REFERENCES}

[1] Kato GJ, Gladwin MT, Steinberg MH. Deconstructing sickle cell disease: reappraisal of the role of hemolysis in the development of clinical subphenotypes. Blood Rev., 2007; 21: 37-47.

[2] Pathare AV, Alkindi SS, Daar S, Dennison D, Cytokines in Sickle cell Disease, Hemat., 2003, 8(5): 329-337.

[3] Wang WC, and Lukens JN: Sickle cell anemia and other sickling syndromes, In Lee, G.R, Foerster J, Lukens J, Paraskevas F, Greer JP and Rodgers GM eds., Wintrobe's Clinical Haematology, 10th Ed. Williams \& Wilkins, Baltimore, Maryland, USA, 1999: 1: 1346-1398.

[4] Rees DC, Williams TN, Gladwin MT. Sickle-cell disease. Lancet 2010; 376: 2018-2031.

[5] Gladwin MT, Vichinsky E. Pulmonary complications of sickle cell disease. N. Engl. J. Med., 2008; 359: 2254-2265.

[6] Aliyu ZY, Gordeuk V, Sachdev V, Babadoko A, Mamman AI, Akpanpe $\mathrm{P}$, et al. Prevalence and risk factors for pulmonary artery systolic hypertension among sickle cell disease patients in Nigeria. Am. J. Hematol., 2008; 83: 485-490.

[7] Reiter CD, Wang X, Tanus-Santos JE, Hogg N, Cannon RO 3rd, Schechter AN, et al. Cell-free hemoglobin limits nitric oxide bioavailability in sickle-cell disease. Nat. Med., 2002; 8: 13831389.

[8] Jison ML, Gladwin MT. Hemolytic anemia-associated pulmonary hypertension of sickle cell disease and the nitric oxide/ arginine pathway. Am. J. Respir. Crit. Care Med., 2003; 168: 3-4.

[9] Rother RP, Bell L, Hillmen P, Gladwin MT. The clinical sequelae of intravascular hemolysis and extracellular plasma hemoglobin: a novel mechanism of human disease. JAMA, 2005; 293: 1653-1662.

[10] Gladwin MT, Schechter AN, Shelhamer JH, Pannell LK, Conway DA, Hrinczenko BW, et al. Inhaled nitric oxide augments nitric oxide transport on sickle cell hemoglobin without affecting oxygen affinity. J. Clin. Invest., 1999, 104: 937-945.

[11] Atz AM, Wessel DL. Inhaled nitric oxide in sickle cell disease with acute chest syndrome. Anesthesiol., 1997, 87: 988-990.

[12] Sullivan KJ, Goodwin SR, Evangelist J, Moore RD, Mehta P. Nitric oxide successfully used to treat acute chest syndrome of sickle cell disease in a young adolescent. Crit. Care Med., 1999, 27: 25632568.

[13] Morris CR, Kuypers FA, Larkin S, Vichinsky EP, Styles LA, Patterns of Arginine and Nitric Oxide in patients with sickle cell disease with vaso-occlusive crisis and acute chest syndrome, J. Ped. Hematol. Oncol., 2000, 22: 515-520.

[14] Gladwin MT, Sachdev V, Jison ML, Shizukuda Y, Plehn JF, Minter $\mathrm{K}$, et al. Pulmonary hypertension as a risk factor for death in patients with sickle cell disease. N. Engl. J. Med., 2004; 350(9): 886-95.

[15] Machado RF, Anthi A, Steinberg MH, Bonds D, Sachdev V, Kato GJ, et al. N-terminal pro-brain natriuretic peptide levels and risk of death in sickle cell disease. JAMA. 2006; 296(3): 310-8.

[16] Castro O, Hoque M, Brown BD. Pulmonary hypertension in sickle cell disease: cardiac catheterization results and survival. Blood. 2003; 101(4): 1257-61.

[17] Abbas AE, Fortuin FD, Schiller NB, Appleton CP, Moreno CA, Lester SJ. A simple method for noninvasive estimation of pulmonary vascular resistance. J. Am Coll. Cardiol., 2003; 41:1021-1027.

[18] Miller AC, Gladwin MT. Pulmonary complications of sickle cell disease. Am J. Respir. Crit. Care Med., 2012; 185(11): 1154-65.

[19] Minniti CP, Sable C, Campbell A, Rana S, Ensing G, Dham N, et al. Elevated tricuspid regurgitant jet velocity in children and adolescents with sickle cell disease: association with hemolysis and hemoglobin oxygen desaturation. Haematol., 2009; 94(3): 340-7.

[20] Oguanobi NI, Ejim EC, Anisiuba BC, Onwubere BJ, Ike SO, Ibegbulam OG et al. Clinical and electrocardiographic evaluation of sickle-cell anaemia patients with pulmonary hypertension. SRN Hematol., 2012; 2012: 768718.

[21] Parent F, Bachir D, Inamo J, Lionnet F, Driss F, Loko G, et al. A hemodynamic study of pulmonary hypertension in sickle cell disease. N. Engl. J. Med., 2011; 365(1): 44-53.

[22] Galiè N, Hoeper MM, Humbert M, Torbicki A, Vachiery JL, Barbera JA, et al.; ESC Committee for Practice Guidelines (CPG). Guidelines for the diagnosis and treatment of pulmonary hypertension: The Task Force for the Diagnosis and Treatment of Pulmonary Hypertension of the European Society of Cardiology (ESC) and the European Respiratory Society (ERS), endorsed by the International Society of Heart and Lung Transplantation (ISHLT). Eur. Heart J., 2009; 30: 2493-537.

[23] Voskaridou E, Tsetsos G, Tsoutsias A, Spyropoulou E, Christoulas D, Terpos E. Pulmonary hypertension in patients with sickle cell/beta thalassemia: incidence and correlation with serum $\mathrm{N}$ terminal pro-brain natriuretic peptide concentrations. Haematol. 2007; 92: 738-743

[24] Machado RF, Hildesheim M, Mendelsohn L, Remaley AT, Kato GJ, Gladwin MT, NT-pro Brain Natriuretic Peptide Levels and the Risk of Death in the Cooperative Study of Sickle Cell Disease, $B r$. J. Haematol., 2011; 154(4): 512-520.

[25] Casserly B, and Klinger JR, Brain natriuretic peptide in pulmonary arterial hypertension: biomarker and potential therapeutic agent, Drug Design, Development and Therapy, 2009; 3: 269-287.

[26] Haque AK, Gokhale S, Rampy BA, Adegboyega P, Duarte A, Saldana MJ. Pulmonary hypertension in sickle cell hemoglobinopathy: a clinicopathologic study of 20 cases. Hum. Pathol., 2002; 33: 1037-43.

[27] Vichinsky EP. Pulmonary Hypertension in Sickle cell disease. $N$. Engl. Med., 2004, 350: 857-859.

[28] Ataga KI, Sood N, De Gent G, Kelly E, Henderson AG, Jones S, et al. Pulmonary hypertension in sickle cell disease. Am. J. Med., 2004; 117:665-669. 